physiology of intra-myocardial blood flow and the pathophysiology of infarction and sudden death. This depth includes a synthesis of the controversy over whether occlusive thrombi are always present in the coronary arteries supplying the territory of segmental infarcts (but it is a pity that there is no reference to the work either of Erhardt or of Fulton in this regard).

Ischaemia of bowel, bone and nerve and muscle are not neglected, nor the effects of hypoxia on tumour growth or the pathology of renal ischaemia and renal necrosis.

The mechanisms, prevention, treatment and consequences of hypoxia in the newborn infant and the pathology of perinatal hypoxia are authoritatively described. Finally we have four chapters devoted to the effects of hypoxia on the nervous system.

This paperback publication can be highly recommended and will have a wide appeal.

\section{Immunology of Gastrointestinal and Liver Disease}

By RALPH WRIGHT. Current Topics in Immunology Series. Pp. 132, illustrated. 1977. Soft cover $£ 4.75$.

This book is one of a series of monographs intended to provide the busy clinician with an up to date appraisal of the relevance of immunology to his own speciality. There are chapters on the basic physiology of the gut and liver as immunological organs, immune deficiency disorders, gastritis, coeliac disease, inflammatory bowel disease, acute and chronic hepatitis, drug and alcohol-induced liver disease, and tumour immunology. Throughout, the text is lucid and the illustrations, although simple, informative. Refreshing in a book of this kind is that the author treats controversial subjects without bias, refraining from dogmatizing with his personal views. The chapter on acute viral hepatitis gives a particularly clear account of the numerous antigens associated with hepatitis B (serum hepatitis) infection. Some unqualified statements are open to question, e.g. that there is no correlation between the presence of $\alpha$-foetoprotein and the hepatitis B surface antigen in hepatocellular carcinoma. Overall, however, the book admirably fulfils a need for the clinical gastroenterologist.

\section{Immunology of the Gut}

Ciba Foundation Symposium 46 (new series). Pp. viii +

376, illustrated. Amsterdam: Excerpta Medica, 1977.

Hard cover $\$ 28.75$ (Dfl. 70.00).

The gut is a potential site of entry for micro-organisms and antigens because absorptive function demands a permissive surface. It is therefore equipped with a large number of immunocytes residing in the lamina propria, the Peyer's patches and the mesenteric lymph nodes. The structural and functional features of this elaborate lymphoid system have until recently perhaps been somewhat neglected by experimental immunologists.

The CIBA symposium reported in this book brought together a well balanced group of 16 immunologists, pathologists and gastro-enterologists who reviewed the present state of knowledge of gut immunology and reported new experimental data. In his introduction the chairman, Professor Peter Lachmann, points out that interaction between immunology and clinical medicine has always very much been two-way, and this statement is well corroborated by the book. Most of the fifteen contributions are of high standard, and in their discussion after each contribution the participants often succeed in generating the type of multi-disciplinary interactions which amplify the data presented and reveal exciting areas for future research.

This is not a book for those who want a comprehensive review on the immunological features of gastro-intestinal diseases. Gastric and liver diseases are for instance not discussed and alimentary or food allergies hardly mentioned.
Indeed the few clinical chapters are not as good as those dealing with basic immunology.

The book makes considerable demands on background knowledge in immunology and research experience. It is highly recommended for both medical and non-medical immunologists and research-orientated gastro-enterologists but it is probably too specialized for the general physician.

\section{Intimations of Quality. Ante-mortem and Post-mortem} Diagnoses

By H. A. Waldron \& Lorna Vickerstaff. Pp. 59, illustrated. London: Nuffield Provincial Hospitals Trust, 1977. Soft cover, $£ 1.50$.

The post-mortem held its pre-eminent role up to the 1950 s. Since then increasing use of organ biopsy in life has contributed to its decline, but not without a struggle. There continues to be a spirited debate between those who regard the post-mortem room as the centre of the forum and those who prefer to assess the functional aspects of disease during life and correlate these with histology before it is too late to do so. This interesting Birmingham hospitals' study analyses the results of data entered on 1126 forms, specially designed so that the clinician completes the first part and the pathologist conducting the post-mortem fills the second part, both using the International Classification of Diseases. In less than $50 \%$ of the cases in this prospective study was the clinical diagnosis of cause of death confirmed at post-mortem. The remaining cases were almost equally split between those in which there was only a minor difference of opinion, and those in which disagreement was total. How so? Surely somebody must have been lying? Which is the suspect link in this clinico-pathological exercise? More important still, did the mistaken diagnoses shorten life? The reviewer does not want to spoil the mystery for the reader by revealing the solution so he recommends that the intellectually curious should dip into this splendid little paperback for a complete analysis and its therapeutic and epidemiological consequences.

Jamieson \& Kay's Textbook of Surgical Physiology (3rd edn). Edited by I. McA. Ledingham \& C. MacKay. Pp. 381, illustrated. Edinburgh, London and New York: Churchill Livingstone, 1978. £18.00.

Perhaps the most important feature of post-war surgical training is the emphasis which has been placed on the basic sciences. To-day's surgeon is not only required to be a skilled technician, but his art has to be firmly founded on the solid foundations of anatomy, pathology and physiology. The very first major hurdle which the trainee must encounter is the Primary Fellowship examination of one of the four Royal Colleges of Surgeons in these islands, in which his knowledge of these three subjects is rigorously tested. It is interesting that many of the great surgical teachers of recent times have themselves made fundamental contributions to our corpus of physiological knowledge and prominent among them is Sir Andrew Kay whose work on gastric secretion and the augmented histamine test is well known. Nearly 20 years ago, Professor Kay, together with his collaborator, Mr Ainslie Jamieson, published the first edition of this text book, which pioneered the standard texts dealing specifically with surgical physiology. This third edition, which appears after too long a gap, has been very completely rewritten. Now the original two authors have been joined by a large team of collaborators - mostly themselves surgeons, but also including physicians, oncologists and a biochemist - under the aegis of two new editors. The result is a completely up to date and readable text, well illustrated and providing an ideal volume for the surgeon in training. As well as covering the major physiological systems, circulation, respiratory system, endocrines, alimentary tract, nervous system and so on, there are specific chapters on wound healing, the biological effects of irradia- 
tion, fluid balance, the metabolic response to injury, immunology as applied to surgery and shock.

It will obviously be of considerable value for the candidate working for his Primary FRCS but all surgeons will find that they can read this excellent book with both interest and profit.

\section{Pathology of Ischaemic Heart Disease}

By Theo Crawford. Pp. $x+170$, illustrated. Sevenoaks:

The Butterworth Group, 1977. Hard cover $£ 10.50$.

Crossing the hyphen between one discipline and another seems both sensible and fashionable for meetings and symposia at which major problems can be attacked from all angles by experts in the different fields. It cannot be doubted that this is good, and in this book, wherein a single distinguished author whose personal discipline is histopathology writes on ischaemic heart disease from several approaches, we have a rather special example. He starts off with the anatomy of the coronary arteries including the physiology of coronary blood flow, goes on to methods of examination of the coronary arteries in the post-mortem room including radiographic and plastic cast techniques. He then considers the pathogenesis of ischaemic heart disease, the pathology of coronary artery occlusion, the pathology of sudden death and of myocardial infarction and its complications. Next are considered the changes in the blood and biochemistry in ischaemic heart disease and the aetioligical factors ranging from sex and geographical differences through dietary and metabolic theories. The evidence for the incrimination of the major risk factors is not omitted and the author adds his weight to the theory that hard water may play a part in augmenting the incidence of ischaemic heart disease.

This is a short book and easy to read. Although it is primarily intended for the trainee pathologist it will be of equal value to cardiologists and senior students with an interest in cardiology. It is highly recommended as representing not only good value for money but good value in information gained per number of words read.

Peripheral Manipulation (2nd edn).

By G. D. Maitland. Pp. 363, illustrated. Sevenoaks: The Butterworth Group, 1977. Hard cover $£ 13.50$.

The practice of manipulation of both vertebral and peripheral joints has become progressively more widespread in Great Britain over the last decade. The most commonly used techniques are manipulation under anaesthetic or those described by Maitland or Cyriax. Each technique has found its supporters in various quarters and some centres find the methods complementary. The second edition of Maitland's book describing the manipulation of peripheral joints is therefore a welcome companion to the new edition of his better known work on vertebral manipulation.

The book is aimed primarily at the physiotherapist or medical practitioner who wishes to develop his knowledge and skill in the field of manipulation and mobilization of peripheral joints. The basic principle of Maitland's manoeuvres is that repeated gentle oscillatory passive movements can be used to relieve joint pain and stiffness. The first section of the book is devoted to expanding this theory with particular emphasis on examination and repeated assessment of joint range. The second section describes in detail, with the help of simple diagrams, the various methods by which each joint may be mobilized. Finally there is a section on methods of assessment of the treatment and of recording ranges of movement which will appeal to research workers in this field.

The author has purposely avoided discussing diagnosis which will undoubtedly disappoint many medical practitioners especially those in general practice who are often faced not only with the problem of treatment of a painful joint and its surrounding soft tissue but the diagnosis as well.
Controlled studies are obviously still necessary to establish the full value of this form of treatment. Meanwhile, this useful book serves to highlight an aspect of physical treatment for the painful stiff joint and will undoubtedly be very helpful to those already using these techniques or those wishing to start.

Postgraduate Nephrology (2nd edn).

By Roger Gabriel. Pp. 238, illustrated. Sevenoaks: The Butterworth Group, 1978. Limp cover $£ 6.75$.

The major changes in the second edition of Postgraduate Nephrology are the addition of multiple choice questions and case histories now obligatory for all books aimed at the MRCP market.

There are, however, one or two errors of fact such as the statement that renin levels are usually reduced in malignant hypertension and that chlorpropamide is of value in nephrogenic diabetes insipidus. In places, there is a surprisingly dated emphasis, notably when the impression is given that ureterosigmoidostomy is the current operation for bladder replacement. In the discussion of renal artery stenosis there is confusion between the urinary excretion and urinary concentration of substances, and the use of essential and benign interchangeability in hypertension is also odd. The spelling in places is frankly eccentric - one only wishes there were such things as nephrogenic streptococci-unhappily they tend to be nephritogenic.

Nonetheless Dr Gabriel's book is readable and lucid, well organized and balanced, and can be recommended as a primer in nephrology.

Practice. A Handbook of Primary Medical Care. Instalment V Edited by J. Cormack, M. Marinker \& D. MORRELl. London: Kluwer-Harrap Handbooks, 1977. £6.50 per instalment (plus special binder at $£ 1.60$ and postage). Updating service planned to cost about $£ 6.00$ p.a.

With the appearance of the fifth instalment, this handbook is now complete. Many of the problems that arose when parts were missing have now been resolved. This, however, exposes a question which the publishers should consider for the future. Now that the complete handbook is available, who is going to purchase it in instalments?

Every cloud has a silver lining. Some of the best sections of this book are to be found in the later instalments and those who were put off by reading isolated chapters earlier should now reconsider whether they ought not to have this book in their practice library. Its value is not confined only to the doctors in the National Health Service in the United Kingdom. The problems presenting in primary care are the same all over the world. This is equally true for the doctor who calls himself a general practitioner, the family doctor, the internist or the paediatrician. The problems as presented by their patients are the same and so, too, are the ways the doctor should be looking at these.

\section{Recent Advances in Medicine. Number 17}

Edited by D. N. Baron, Nigel Compston \& A. M. DAwSON. Pp. 473, illustrated. 1977. Cased edition $£ 12.00$. Soft cover $£ 9.00$.

There are many hours of enjoyable reading amongst the eighteen chapters in the latest Recent Advances in Medicine. None is other than well written, with up to date information and bibliographies. There are some excellent reviews of topics in the main stream of general medicine, such as hepatitis, hyperlipidaemia and cardiovascular disease, bile salts and gall stones, gastro-intestinal hormones, the endocrinology of the hypothalamus and antibacterial chemotherapy. Malignancy gets a generous share, with chapters on epidemiology, Hodgkin's disease, non-Hodgkin's lymphoma and acute 